\title{
THE DURABILITY AND WEAR OF COATED MILLS FROM HSS-PM IN STAINLESS STEEL CUTTING WITHOUT CUTTING FLUID
}

\author{
BELAN, M[iroslav] \& MICHALIK, P[eter]
}

\begin{abstract}
This article presents the test results of milling tools of high speed steels prepared via powdered metallurgy that were applied when machining austenitic chromium-nickel steels. Our aim was to demonstrate the capabilities and limitations of highspeed steels as a material for cutting tools, if they are machined difficult to machined materials. During the testing was monitored and evaluated wear on the clearance surface of the cutting wedge. Equally was the resulting surface roughness and vibration of spindle at the selected cutting conditions measured. On the durability testing of tools, we tried to load the milling cutters as much as possible. Therefore the austenitic chromiumnickel steel (1.4301) was chosen as machined material. The milling tools worked by up milling and without using of coolant._Based on the test results have been selected the best cutting conditions for machining and also modifications were proposed for further testing.
\end{abstract}

Keywords: HSS-PM tools, durability, wear, up-milling, stainless steels

\section{INTRODUCTION}

In general the usage of cutiing tools made from High Speed Steels is strongly limited with their hot hardness. However tools from HSS have the highest bend strength and the highest toughness among all cutting materials. HSS tools are used in preference in areas where is a change of amplitude and frequency of cutting forces. They are suitable for special and difficult machining conditions such as nonhomogeneous material, holes welding joints and stacked plates. Other increasing of qualitative properties is possible during Powder Metallurgy. The Asea Stora process enables to prepare a substrate with higher compositional flexibility of alloying components, with higher purity and with regular and homogenous structure. For increasing of hot hardness and decreasing of friction coefficient it is used PVD coating. Specific area, in which we can apply the HSS-PM tools, is the machining of stainless steels by low cutting speeds, but by high rate of axial and radial cutting depth. Our research was based on scietific articles $[1,2,3,4,5,6,7,8]$. In our case we try to load milling cutters during the testing as much as possible. It was applied up-milling whitout using of coolant and the machined material was the austenitc chromium-nickel steel (n.1.4301). We measured the wear on the clearance surface of mills, also the roughness of machined surface and the vibratins on the spindle. $[1,2,3,4,5,6,7,8]$

\section{RESEARCH IN MACHINING WITH TOOLS FROM HSS AND IN MACHINING OF STAINLESS STEELS}

To milling of stainless steels are usually used coated tools made from sintered carbides. But these tools can be effective by milling of austenitic steels in range of cutting speeds between $30-40 \mathrm{~m} / \mathrm{min}$. However, in this case the usage of sintered carbides has also limitations: decreasing of wear by cutting speeds higher then 40 $\mathrm{m} / \mathrm{min}$. and high risk of fracture by cutting speeds lower then $30 \mathrm{~m} / \mathrm{min}$., when unstable BUE is creating. According to research realized in area machining of titanium alloys with tools from HSS-PM, we applied similar conditions in our tests. Despite references mentioned in technical literature to use down-milling when stainless steel is machining, we used up milling without the use of cutting fluids. We want with these conditions a higher load of milling cutter to achieve. We observed the influence of unfavourable primary phase of up-millng to wear on the clearance surface. Machining without cutting fluinds decreases the environmental ballast on living environment. Even if they were applied lower cutting speeds and feeds per minute, the cutting performance was well-preserved thanks to higher axial depth of cut. Cutting tools from HSS has a great advantage against tools from sintered carbides. They can be over worn resharpening. So we can onto costs for a single tools, use this tool minimum two times.[1,2]

\subsection{Milling cutters from HSSE-PM}

We used HSSE-PM shank mills for testing. The shank mills were coatend with AlTiN coat, which is possible to apply for dry machining. The friction coeficient of this coat is 0.45 and the hardness is 3000$3500 \mathrm{HV}$.

\begin{tabular}{|c|c|}
\hline Diameter of shank mill ФD & $8 \mathrm{~mm}$ \\
\hline Diameter of tool shank Фd & $10 \mathrm{~mm}$ \\
\hline Total length L & $88 \mathrm{~mm}$ \\
\hline Length of workinkg part 1 & $38 \mathrm{~mm}$ \\
\hline Type of shank mill & $\begin{array}{c}\text { N- for univerasal use for } \\
\text { materials with } \mathrm{R}_{\mathrm{m}}=900 \mathrm{MPa}\end{array}$ \\
\hline Helix angle $\lambda$ & $30^{\circ}$ \\
\hline Rake angle $\gamma$ & $12^{\circ}$ \\
\hline Substrate used for tools & $\begin{array}{c}\text { HSSE-PM- high performance } \\
\text { steel with homogeneous } \\
\text { microstructure, with higher } \\
\text { wear resistance and higher } \\
\text { dimensional constancy }\end{array}$ \\
\hline Spacing of teeth/teeth & regular/4 \\
\hline PVD coating & $\begin{array}{c}\text { AlTiN, thickess } 1-4 \mu \mathrm{m}, \\
\text { hadness 38GPa }\end{array}$ \\
\hline Tab. 1. Parameter of used shank mills &
\end{tabular}

\subsection{Machined material: 1.4301 steel}

This material is due to its ability to resist corrosion in aggressive environments used in the chemical, petrochemical, food and automotive industries. The 
1.4301 steel is very difficult to machine for several reasons. The chemical composition, concrete the high content of chromium markedly decreases the thermal and electrical conductivity. So the heat form primary and secondary plastic deformation isn't divert from the cutting zone in preference by chips and also the extension of heat beck to the material is limited. The reduced thermal conductivity causes diffusionless shear transformation of austenite to martensite. This creates a very hard layer, that is difficult to machine. Therefor it's appropriate to apply cutting conditions, so that the machined material is not exposed to high strain rate. The remaining heat in the cutting zone affects the tensibility and the yield strength. If the temperature increases, increases also the tensibility and the yield strength decreases. With the influence of processional factors we get a very hard to machine material.[1,9]

\section{DURABILITY TESTS}

\subsection{Cutting conditions}

Initial cutting conditions were chosen based on the references of two tool manufacturer websites, who produce tools from HSS-PM. Both sources are given for finishing machining conditions similar: approximately $\mathrm{v}_{\mathrm{c}}$ $=30 \mathrm{~m} / \mathrm{min} ., \mathrm{a}_{\mathrm{p}}=1-2 \mathrm{x} \Phi \mathrm{D}[\mathrm{mm}] \mathrm{a}_{\mathrm{e}} \mathrm{x} \Phi \mathrm{D}=0.1$ to 0.2 [mm], $\mathrm{f}_{\mathrm{z}}=0.012$ to $0.02 \mathrm{~mm}$. The tool overhang was 50 $\mathrm{mm}$ in each test. These conditions were within a few test passes tested, but working under these conditions was accompanied by a characteristic sound, generated by the tool vibration, which was clearly reflected in the machined surface. This vibration could be induced by the tool overhang and by the aplicated kinematics of millingup milling. So the tool could be push away from cut, because the tool enters the cut with zero depth of cut. To reduce the vibrations, we reduce the cutting speed and feed per tooth. [1,2]

\begin{tabular}{|c|c|c|c|}
\hline $\begin{array}{c}\text { Cutting speed } \\
\mathrm{v}_{\mathrm{c}}[\mathrm{m} / \mathrm{min} .]\end{array}$ & $\begin{array}{c}\text { Feed per tooth } \\
\mathrm{f}_{\mathrm{z}}[\mathrm{mm}]\end{array}$ & $\begin{array}{c}\text { Axial depth of } \\
\text { cut } \mathrm{a}_{\mathrm{p}}[\mathrm{mm}]\end{array}$ & $\begin{array}{c}\text { Radial depth } \\
\text { of cut } \mathrm{a}_{\mathrm{e}}[\mathrm{mm}]\end{array}$ \\
\hline 12,56 & 0,012 & 8 & 0,5 \\
\hline 13,82 & 0,012 & $8,12,18$ & 0,5 \\
\hline 16,6 & 0,012 & $8,12,18$ & 0,5 \\
\hline 19,9 & 0,012 & $8,12,18$ & 0,5 \\
\hline
\end{tabular}

Tab. 2. Modified cutting conditions

\subsection{Wear and durability of shank mills}

According the ISO norm 8688 we divided the active part of the cutting edge into sections, in which the wear was measured. The resulting wear was observed by microscope NJC 160 and evaluated by software Motic Images Plus 2.0. On the cutting edges come into existence these types of wear: fatigue fracture on the point of cutting wedge,abrasive wear on the clearance surface,cratering of cutting edge, irregular cracks on the clearance surface,specific wear on the clearance surfacemay be a violation of deposited coatings. By the identification of the causes of several types of wear is necessary to take in reflections certain factors. Whereas was applied up milling, where the cutting begins from zero thickness of cutted layer, the point of cutting wedge and the section of cutting edge directly behind the point entered into the engangement as first. These exposed parts of cutting wegde had to overcome the resistance of the material to deformation (tensibility). Also the compression of the machined material under the cutting edge in the initial phase of cutting was most intense, therefore with effect of high temperatures and friction came into existence most intense wear.

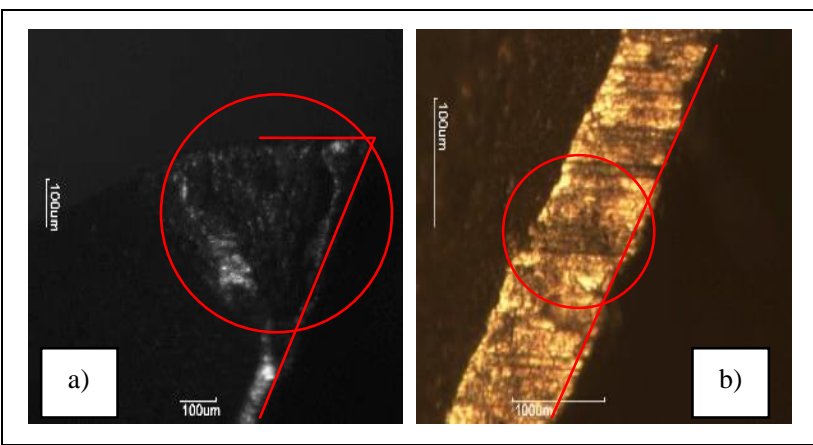

Fig. 1. a) fatigue failure on point of cutting wedge, b) abrasive wear on the clearance surface (the red line marks the cutting edge)

This initial adverse phase of up milling has also negative influence on the hardening of tooled material, what can cause to problems in the other passing of shank mill, where the tooth begins the cutting into the hardened material, whose structure is totalled by martensite. The consequence is higher cyclic loading of cutting wedge. It is also necessary to consider pushing away of mill from the cut, whereby may arise surface waviness. The enganged cutter can be so secondary activated and the cutting wedges exposed to cyclic loading and relaxation due to changes in cross-section of cutting chips. By excessive wear of the point of cutting wedge and of the section directly behind the point were observed unclaimed deformend remains of material.

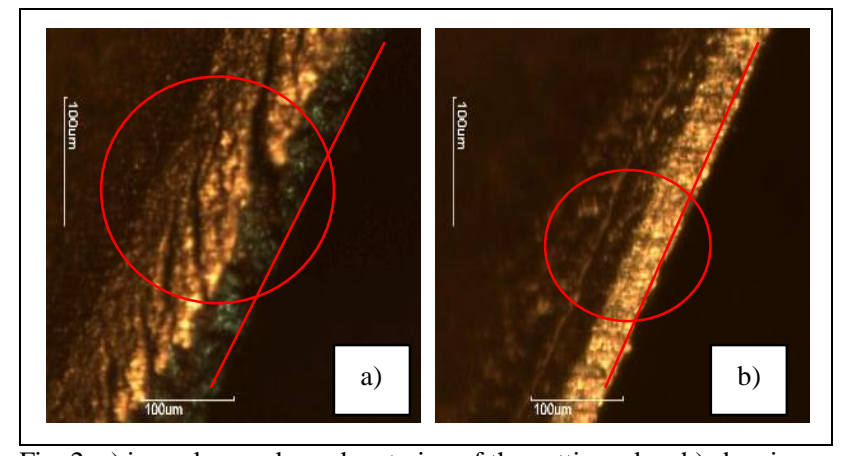

Fig. 2. a) irregular cracks and cratering of the cutting edge, b) abrasive wear and clearly delimited area (the red line marks the cutting edge)

The cratering of cutting edge was induced by peak loads typical for interrupted cuts. By the machining with using of radial depth of cut $0.5 \mathrm{~mm}$, it was necessary to take into account the removing of the maximum compressive stress emergent on the cutting wedge from the area where would otherwise arise a crater in places closer to the cutting edge. The cyclic repetition of the mentioned load can cause peak loads. On the clearance surface of shank mills, which worked at the axial depth of cut $18 \mathrm{~mm}$ were observed irregular cracks. Based on the axial immersion and spacing of teeth of mills we can conclude that if the first tooth leaved the cut, the next tooth already entered the cut. In the cut were located two teeth at the same time, so occurred to generating of more heat and thus increase the temperature in the cutting zone, what caused thermal shocks. In some cases was besides the abrasive wear on the clearance surface observed also markedly delimited surface, where with the influence of elastoplastic zone in the machined material under the clearance surface of mill may occure to 
dismantling of deposited coating AlTiN. As criterion value to determine the criteria of durability were two values choosen: maximum value of $\mathrm{VB}=300 \mu \mathrm{m}$ - as the maximum wear in the indiferent point on the active section of cutting edge, average value of $\mathrm{VB}=100 \mu \mathrm{m}$ - as the average value of wear on the active section of cutting edge.

The maximum value of wear $\mathrm{VB}=300 \mu \mathrm{m}$ was selected to identify the most worn of the cutting edge and the clearance surface. The average wear was chosen to obtain a comprehensive view on the wear of the active part of cutting edge.

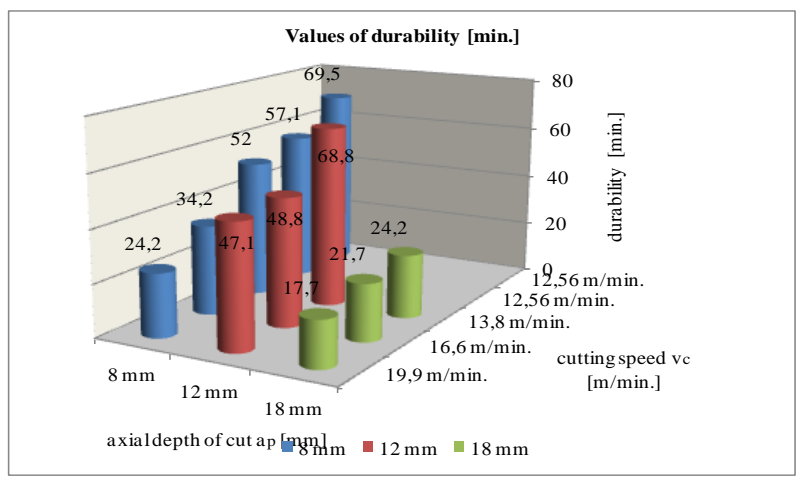

Fig. 3. Values of durability

The graph on figure 3 is created from values of durability for criterion average $\mathrm{VB}=100 \mu \mathrm{m}$. Depending on the graphical dependence is possible to confirm the impact of increasing cutting speed to decrease durability. In case of impact valuation of axial depth of cut is necessary to take into account the tool overhang (by each tool $50 \mathrm{~mm}$ ). By the machining with usage of axial depth of cut $a_{p}=8 \mathrm{~mm}$ was recorded a significant tool instability. This was reflected in the durability and also the roughness of the machined surface.

\section{ROUGHNESS OF MACHINED SURFACE}

For evaluation of machined surface roughness were $\mathrm{Ra}$ and $\mathrm{Rz}$ parameters used. The machined surface was divided into three sections, which were used to test the roughness. The division machined surface depends on the applied axial depth of cut and this division enabled to relate resulting roughness to the wear along the cutting edge. The highest values of both roughness parameters were measured in the lower section namely for all cutters. This was a section of machined surface generated by cutting edge just behind the point of the cutting wedge in difficult conditions of initial phase of up-milling. However, under the applied conditions and kinematics of milling process is concerned expected process of deterioration of surface roughness. In several consecutive measurements of surface roughness, resulting from machining with the same shank mill, there was a fluctuation in the values of roughness parameters. Possible explanation is the presence and the unstability of buil up edge (BUE), which could significantly change the geometric characteristics of the cutting wedge and the conditions of chip removal. Another possible cause could be a variation in the measured area on the divided sections. With increasing of wear on the clearance surface of cutting weges fully began to manifest the reduced yield strength and tensibility of austenitic steel, so the worn cutting edge failed to properly cut the material. Increasigly there was pull-out of machined material. Just before the end of machinig, was observed on the machined surface the texture with "slivers". The mentioned texture of the machined surface is characterized as longitudinal roughness measured in the direction of the cutting velocity vector. This texture was created due to the reduction of the clearance angle of the main clearance surface as a result of wear. So came into being a change in the radius of curvature of the cutting edge and that caused by small depths of cut the impression of material under the cutting edge. Just by the cohesion of material with the clearance surface came into being a elastic and plastic deformation, which caused the creation of the above-mentioned slivers.

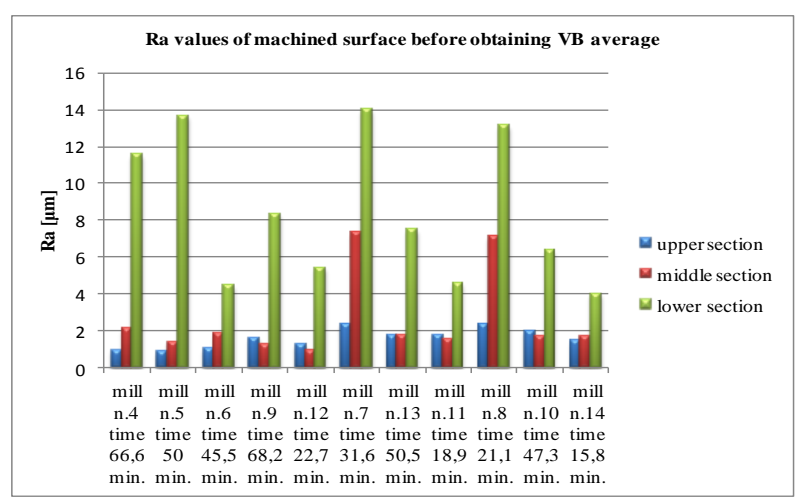

Fig. 4. Measured Ra values

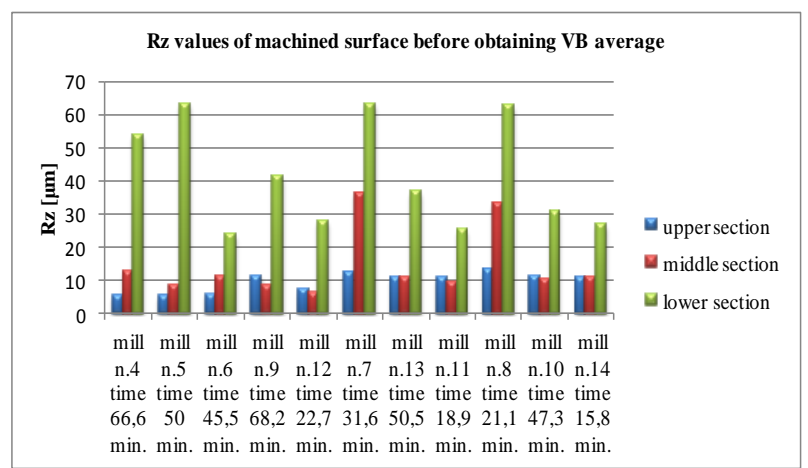

Fig. 5. Measured Rz values

Comparing the working time of the graphical dependencies is clear that $\mathrm{Ra}$ and $\mathrm{Rz}$ values were lowest in machining with shank mills n.9, 10 and 13. These mills worked by axial depth of cut $a_{p}=12 \mathrm{~mm}$. Equally is evident that by machining with mills n.4,5,6,7 and 8 were the parameters of roughness values the highest, which resulted partially from wear and instability of the cutting process. These mills worked by axial depth of cut $a_{p}=8$ $\mathrm{mm}$. By the machining with mills n.11,12 and 14 were obtained roughness values comparable to those obtained in the case of mills n.9,10 and 13, but the machining time was significantly shorter. The big problem presented the lower measured section where cutting ran under difficult conditions already reported. In the case of eliminating of the unfavorable initial cutting phase during the change of up-milling to down milling, would be possible with using of appropriate conditions $\left(\mathrm{a}_{\mathrm{p}}=12 \mathrm{~mm}, \mathrm{v}_{\mathrm{c}}=13.82\right.$ to 19.9 $\mathrm{m} \mathrm{/} \mathrm{min.)} \mathrm{remain} \mathrm{throughout} \mathrm{the} \mathrm{durability} \mathrm{within}$ favorable values of roughness 


\section{STABILITY OF MILLING FOR CHOOSEN CUTTING PARAMETERS}

During the machining were vibrations on a spindle of CNC-milling machine monitored under conditions specified in table 3 (for each axial depth one mill monitored).

\begin{tabular}{|c|c|c|c|c|}
\hline Mill n. & $\begin{array}{c}\text { Cutting } \\
\text { speed } \\
\mathrm{v}_{\mathrm{c}}[\mathrm{m} / \mathrm{min} .]\end{array}$ & $\begin{array}{c}\text { Axial } \\
\text { depth of } \\
\text { cut } \mathrm{a}_{\mathrm{p}}[\mathrm{mm}]\end{array}$ & $\begin{array}{c}\text { Radial } \\
\text { depth of } \\
\text { cut } \mathrm{a}_{\mathrm{e}}[\mathrm{mm}]\end{array}$ & $\begin{array}{c}\text { Feed pre } \\
\text { minute } \\
\mathrm{f}[\mathrm{mm} / \mathrm{min} .]\end{array}$ \\
\hline $\mathrm{n} .6$ & 13,82 & 8 & 0,5 & 26,4 \\
\hline $\mathrm{n} .13$ & 16,6 & 12 & 0,5 & 31,68 \\
\hline $\mathrm{n} .14$ & 19,9 & 18 & 0,5 & 38 \\
\hline
\end{tabular}

Tab. 3. Monitored cutting conditions

With the accelerometer SKF CMSS 3811 were captured velocity changes and acceleration in a direction normal to the sliding movement of the workpiece (marked y) and in the opposite direction to the sliding moovment of workpiece (marked $\mathrm{x}$ ). For measuring was the filter E1 used, which displays the envelope curve of acceleration amplitude by frequency $50 \mathrm{~Hz}$. By means of integration we got the RMS value from this curve, which are displayed in table 4.

\begin{tabular}{|l|c|c|c|c|c|c|}
\hline RMS & $\begin{array}{c}\text { mill } \\
\text { n.6-X }\end{array}$ & $\begin{array}{c}\text { mill } \\
\text { n.6-Y }\end{array}$ & $\begin{array}{c}\text { mill } \\
\text { n.13- } \\
\mathrm{X}\end{array}$ & $\begin{array}{c}\text { mill } \\
\mathrm{n} .13- \\
\mathrm{Y}\end{array}$ & $\begin{array}{c}\text { mill } \\
\mathrm{n} .14- \\
\mathrm{X}\end{array}$ & $\begin{array}{c}\text { mill } \\
\mathrm{n} .14- \\
\mathrm{Y}\end{array}$ \\
\hline $\begin{array}{l}\text { beginn } \\
\text { ing of } \\
\text { cutting }\end{array}$ & $\begin{array}{c}1,45^{*} \\
10^{-3}\end{array}$ & $\begin{array}{c}2,7 * \\
10^{-4}\end{array}$ & $\begin{array}{c}6,37^{*} \\
10^{-4}\end{array}$ & $\begin{array}{c}1,4^{*} \\
10^{-4}\end{array}$ & $\begin{array}{c}1,22^{*} \\
10^{-3}\end{array}$ & $\begin{array}{c}1,33^{*} \\
10^{-4}\end{array}$ \\
\hline $\begin{array}{l}\text { ending } \\
\text { of } \\
\text { cutting }\end{array}$ & $6^{*} 10^{-2}$ & $\begin{array}{c}2,7^{*} \\
10^{-3}\end{array}$ & $\begin{array}{c}1,03^{*} \\
10^{-3}\end{array}$ & $\begin{array}{c}1,46^{*} \\
10^{-4}\end{array}$ & $\begin{array}{c}1,36^{*} \\
10^{-3}\end{array}$ & $\begin{array}{c}1,41^{*} \\
10^{-4}\end{array}$ \\
\hline
\end{tabular}

Tab. 4. RMS values from envelope curve of acceleration amplitude

We can see, that the enormous change of RMS value occurred by machining with mill n.6, where the accelerometer was fixed on the spindle in the opposite direction to the sliding moovment of workpiece (marked $\mathrm{x}$ ). In all cases of monitoring, we can see that just in the direction of the workpiece movement is the mill less stable. This instability indicates the adverse conditions in the initial phase of up-milling. In the normal direction to the workpiece sliding movement were the tools less intensive pushed away from cut. In terms of stability and durability it can be concluded, that the mill n.13 worked in most stabile conditions.

\section{CONCLUSION}

From the obtained results of durability, it is clear that the chosen up-milling largely negative impact on the course and type of tool wear. Due to the choosen operating tool movement a fatigue fracture at the point of cutting wedges arose, what caused the creation of the machined surface with high roughness In these adverse conditions wasn't the material cut. The material was in this case deformed and ripped out. In terms of choosen machining conditions it is necessary establish following. Due to the chosen cutting speeds in the range of 12-20 $\mathrm{m} / \mathrm{min}$. we did not avoid the creation of build-up edge, which had an adverse effect on cutting conditions. Due to the small radial depth of cut, there was a shift of the maximum compressive stress in the area closer to the cutting edge, resulting in chipping of cutting edge. The used tools had a length of working part equal $38 \mathrm{~mm}$ what was in terms of variability of the axial depth suitable, but in terms of stability of the tool meant the overhang of tools equal $50 \mathrm{~mm}$ the increasing of tool vibration. This increase was most pronounced in the case of using the axial depth of cut $a_{p}=8 \mathrm{~mm}$. In terms of statistical planning and processing of experiments it should be noted that the results are obtained in a narrow range of cutting conditions, which significantly affects the predicative value of the tests. In carrying out of additional tests of cutting properties of high speed steels we suggest the following adjustments:

- a change of up-milling to down-milling, the tool will enter into the cut with maximum cutting thickness of the layer and eliminating the unfavorable initial phase of the up-milling,

- to increase the stability of machining with the use of tools with uneven spacing of teeth or reducing the overhang of tool

- in terms of statistical analysis and predicative value of realized tests is necessary to use the planned experiment

- in terms of cutting perfomance use cutters larger diameter

\section{REFERENCES}

[1] Bach, P. (2009). HSS-PM tools for powerful and economical machining of titanium alloys (in Czech language), Available from: http://www.infocube.cz/images/machiningtooling/clanky/CVUT_HSS\%20nastroje $\% 20 z \% 20 \mathrm{PM} \% 20$ oceli $\%$ 20pro\%20vykonne\%20a\%20ekonomicke\%20frezovani\%20titano vych\%20slitin_50.pdf Accessed:2009-02

[2] Bach, P. (2008). Milling of Titanium Alloys Using HSS Tools Made of PM Steels (in Czech language), Available from: http://web.tuke.sk/fvtpo/journal/pdf07/4-str-05-07.pdf

[3] Deng, J.; Zhou, J.; Zhang, H.; Yan, P.(2011). Wear mechanisms of cemented carbide tools in dry cutting of precipitation hardening semi-austenitic steels, Available from:: http://www.sciencedirect.com/science/article/pii/S004316481100 007X

[4] Jakubéczyová, D. Evaluation of Durability for Cutting Edge on PM Tools Coating by PVD-method (in Slovak language), Available from: http://web.tuke.sk/fvtpo/journal/pdf08/2-str-2125.pdf

[5] Monková, K.; Monka, P.; Vegnerová, P.; Čep, R.; Müllerová, J.; Bražina, D.; Duspara, M. (2011). Factor analysis of the abrasive waterjet factors affecting the surface roughness of titanium. Technical Gazette, Vol. 18, no. 1, (2011) p. 73-77., ISSN 13303651, Available from: http://hrcak.srce.hr/index.php?show=toc\&id_broj=5252

[6] Miskovicova, M.; Faberova, M.; Monka, P.; et al. (1997). New high alloyed steels prepared via powder metallurgy, Proceedings of EUROMAT 97, the 5th European Conference on Advanced Materials and Processes and Applications: Materials, Functionality \& Design, Vol. 1. Metals And Composites, location: Maastricht, Netherlands, Date: APR 21-23, 1997, Book Editor(s): Sarton, LAJ; Zeedijk, HB, Pages: 665-668 Published: 1997

[7] Čuma, M.; Zajac, J. (2012). The impact analysis of cutting fluids aerosols on working environment and contamination of reservoirs. Tehnički vjesnik, Vol. 19, no. 2 (2012), p. 443-446. - ISSN 13303651

[8] Jurko, J.; Džupon, M.; Panda, A.; Zajac, J. (2012). Study influence of plastic deformation a new extra low carbon stainless steels XCr17Ni7MoTiN under the surface finish when drilling. Advanced Materials Research, Trans Tech Publications, 538-541 p, www.scientific.net/AMR.538-541.1312, ISSN 1022-6680, p.1312-1316, Switzerland, Zurich

[9] Pešlová, F.; Hajduchová, L. (2008) Thermomechanically stressed Cr-Ni austenitic steels, METAL 2008, 13.-15.5.2008, Hradec nad Moravicí, ISBN: 978-80-254-1987-8, Available from: http://www.metal2012.com/files/proceedings/metal_08/Lists/Papers/021 